\title{
ABWASSERBIOLOGISCHE KURSE
}

IM JAHRE I956

Unter der Lcitung von Prof. Dr. R. Demoll und Prof. Dr. H. J.IEbmanN, Bayerische Biologische Versuchsanstalt, München, finden die abwasscrbiologischen Kurse im Jahre i956 an folgenden Terminen statt:

Einfübrungskurs vom 5. bis 9. März 1956

Fortbildungskurs rom 8 . bis 12 . Oktoher 1956

Anmeldung für den Einführungskurs bis zum 25. Februar 1956, für den Fortbildungskurs bis zum 22. September r956 an Herrn Prof. Dr. Hans I.Iebmann, Bayerische Biologische Versuchsanstalt, Veterinärstrasse I 3, München 22. Jede weiterc Auskunft ist bei den Veranstaltern erhältlich. 